\title{
Calculation of the Ampacity of High Voltage Cables Laid in Free Air
}

\author{
MILADIN R. TANASKOVIĆ, Frelance consultant, Belgrade
}

\author{
Stručni rad \\ UDC: 621.315 .21 .072 .1 \\ DOI: 10.5937/tehnika1801087T
}

\begin{abstract}
The paper presents various approaches for determining the current rating of three $110 \mathrm{kV}$ cables in trefoil formation laid in free air including the developed finite element method. All models are possible to consider all circumstances affecting the ampacity of cables including the heat transfer to the surrounding ambient by radiation and convection, as well as the effect of solar heating. It has been shown that all available approaches have provided results that match with a reasonable accuracy. The permissible current rating for the three AC cables in trefoil formation laid in free air are calculated in summer for both, cables protected from solar radiation and directly exposed to solar radiation. Also, the time constants for heating-cooling cycle for the considered bunch of cables are calculated. It is important to note that the ampacity of three cables in trefoil formation, by all methods, determined by omitting the cooling by wind in order to obtain results for the worst conditions.
\end{abstract}

Key words: Ampacity of HV cables laid in free air, FEM and analytical methods, three cables in trefoil formation

\section{INTRODUCTION}

The investigations concerning the continuous current rating of self-supporting insulated cable bunches have been motivated by a wide application of these cables in distribution networks. The full utilization of the cable material is only possible if the maximum allowable loads are known for the existing ambient conditions. In the past, various valuable analytical approaches have been elaborated addressing the continuous current rating of cables [1], [2]. An analytical method has been developed for calculating the heating of cable bundles laid out in air in buildings [3], in steady state and transient conditions. The methods for the calculation of the continuous current rating have been also proposed in [1], [4]. Analytical approaches concerning the ampacity of overhead lines generally have been presented in [5], [6]. The idealizations introduced in modelling various structural details and materials, inevitable in analytical approaches, reflect to some extent upon the obtained results. A detailed modelling of cable provides the method of finite elements. This method has been used for a transient temperature analysis

Author's address: Miladin Tanaskovic, freelance consultant for Electrical Power Systems, Zemun Pregrevica 86

e-mail: tanasfam@gmail.com

Paper received: 28.09.2017.

Paper accepted: 18.12.2017. due to step function loads for cables laid in uniform environment [7]. A finite element mesh generator for thermal analysis of underground cables has been suggested [8], considering only the heat transfer by conduction. Such a model has also been elaborated for the evaluation of the ampacity of cables laid inside retaining ducts [9].

The finite element model for the evaluation of the ampacity of underground cables, elaborated in reference [10], has taken into account the drying out of soil and the heat transfer by convection from the soil surface. An enhanced version of this model, elaborated in reference [11], incorporating the radiation and solar heating effects. The latter model, for determining the current rating of the bunch of self-supporting insulated $10 \mathrm{kV}$ cables, adequately adapted in reference [12], has been applied in this paper for comparison with analytical approaches.

\section{FINITE-ELEMENT MODEL}

\subsection{Mathematical model}

The general form of the transient temperature equation for the subspace of cables under consideration, partitioned into a network of finite elements with $N$ nodes, is

$$
[C] \frac{d[\vartheta(t)]}{d t}+[K][\vartheta(t)]=[R(t)]
$$


In (1), $[\vartheta(t)]$ is $N$ dimensional column vector of temperatures of nodes, $[C]$ is $N$ by $N$ heat capacitance matrix, $[K]$ is $N$ by $N$ heat conductance, natural and forced convection and radiation matrix and $[R(t)]$ is $N$ dimensional heat load vector stemming from the internal heat generation, surface convection, and solar heating. Parameter matrices in (1) are

$$
\begin{aligned}
& {[K]=\left[K_{c}\right]+\left[K_{h}\right]+\left[K_{r}\right]} \\
& {[R(t)]=\left[R_{Q}(t)\right]+\left[R_{h}(t)\right]+} \\
& +\left[R_{r}(t)\right]+\left[R_{s}\right]
\end{aligned}
$$

Indices $c, h, r$ and $s$ in (2) and (3) refer to conduction, convection, radiation and solar heating, respectively [11]. Index $Q$ refers to the internal heat generation. The Joule losses in phase conductors and metallic sheaths have been taken into account as well as the dielectric losses in the insulating materials. Triangular finite elements have been used in this analysis.

The matrices figuring in (1) - (3) have been obtained by transferring the corresponding relationships for elements written for their nodes in local coordinates [11] to entire network numbering scheme. Expressions (2) and (3) in their general form are relevant only for the boundary elements with edges on the outer surface of cables. For all other nodes only $\left[K_{c}\right]$ and $\left[R_{Q}(t)\right]$ on the right hand sides of these expressions are not null matrices.

The coefficient matrices in equations (1) - (3) for a triangular element, in its local coordinates, are as given in $[7,10,11$, and 13$]$. They are complemented by relationships for heat load vector from specified surface heating, radiation and solar heating (Appendix A).

After discretization for a minor step $\Delta t$, (1) converts into a simple recurrent relationship for determining temperature variation in time [13]

$$
\left[K_{E}\right]\left[\vartheta\left(t_{n+1}\right)\right]=\left[R_{E}\left(t_{n+1}\right)\right]
$$

where

$$
\begin{aligned}
& {\left[K_{E}\right]=\gamma[K]+\frac{[C]}{\Delta t}} \\
& {\left[R_{E}\left(t_{n+1}\right)\right]=[-(1-\gamma)[K]+(1 / \Delta t)[C]] \cdot\left[\vartheta\left(t_{n}\right)\right]} \\
& +(1-\gamma)\left[R\left(t_{n}\right)\right]+\gamma\left[R\left(t_{n+1}\right)\right]
\end{aligned}
$$

with $\gamma$ as the integration stability factor. In this analysis $\gamma=1$ and $\Delta t=2 \min$ have been adopted, assuring a good accuracy for modest calculation time.

The expressions for determination of characteristic parameters figuring in (1) are given in the subsections below.
The convection coefficient $h$ figuring in expressions for $\left[K_{h}\right]$ and $\left[R_{h}\right]$ is calculated as $[14]$

$$
h=0.632\left(\frac{\frac{9}{5} \vartheta+32}{D_{s}}\right)^{1 / 4} W \cdot m^{-2} \cdot K^{-1}
$$

with

$$
\vartheta=\frac{\vartheta_{s}+\vartheta_{a}}{2}
$$

Here, $D_{s}(m)$ is the overall diameter of the cable bunch, and $\vartheta_{\mathrm{s}}$ and $\vartheta_{\mathrm{a}}$, in ${ }^{\circ} \mathrm{C}$, are cable surface and ambient temperatures respectively. By inserting $\vartheta$ value from Eq. 8 into Eq.7 the same value for $h$ can be used when calculating matrix $\left[K_{h}\right]$ and vector $\left[R_{h}\right]$.

\subsection{Linear approximation of the heat transfer by radiation}

The heat flux emitted by the radiation from a body at temperature $\vartheta$ equals

$$
R=\sigma \varepsilon_{0}(\vartheta+273)^{4}
$$

with $\sigma=5.67 \cdot 10^{-8} \mathrm{~W} /\left(\mathrm{m}^{2} \mathrm{~K}^{4}\right)$ designating the radiation constant and $\varepsilon_{0}=0.95$ being the emissivity constant for the cable outer sheath $[2,5]$. For a modest range of temperatures $\left(\vartheta_{1}, \vartheta_{2}\right)$ expression (9) can be approximated by a linear function satisfying the relationship

$$
g_{0} \int_{\vartheta 1+273}^{92+273} d \vartheta=\sigma \varepsilon_{0}\left[\left(\left(\vartheta_{2}+273\right)^{4}\right)-\left(\left(\vartheta_{1}+273\right)^{4}\right)\right]
$$

Using (10), we obtain for slope $g_{0}$ of the approximating function

$$
g_{0}=\frac{\sigma \cdot \varepsilon_{0} \cdot\left[\left(\vartheta_{2}+273\right)^{4}-\left(\vartheta_{1}+273\right)^{4}\right]}{\left(\vartheta_{2}-\vartheta_{1}\right)}
$$

which is an alternative, enhanced version of the approximation suggested in [11].

If the heat dissipated in the air from the surface of the cable should be determined, then for $\vartheta_{1}$ and $\vartheta_{2}$ the minimum and maximum temperatures for the outer sheathshould be inserted.

The peak temperatures of the outer sheaths of cables have been assessed to be within the interval (40 ${ }^{0} \mathrm{C}, 65{ }^{0} \mathrm{C}$ ). By inserting these extreme temperature values in (11) we obtain

$$
g_{0}=7.4415 \mathrm{~W} \mathrm{~m}^{-2} \mathrm{~K}^{-1}
$$

The ambient (air) radiation, being thermal load for cables, can also be approximated by a linear function. The slope of this function can be determined using (11) 
with $\vartheta_{1}$, and $\vartheta_{2}$ being extreme air temperatures during the period under consideration.

For winter air temperatures, ranging from $-20{ }^{0} \mathrm{C}$ to $10{ }^{\circ} \mathrm{C}$, in extreme cases, the slope of the approximation function equals

$$
g_{01}=4.1603 \mathrm{~W} \mathrm{~m}^{-2} \mathrm{~K}^{-1}
$$

For summer air temperatures, ranging from $10{ }^{\circ} \mathrm{C}$ to $40{ }^{\circ} \mathrm{C}$, Eq. 11 gives

$$
g_{01}=5.7163 \mathrm{~W} \mathrm{~m}^{-2} \mathrm{~K}^{-1}
$$

\subsection{Solar heating}

The maximum heat emitted from the sun to the earth surface is $E=0.65 \mathrm{~kW} / \mathrm{m}^{2}$ in winter, and $E=1.353 \mathrm{~kW} / \mathrm{m}^{2}$ in summer. For Belgrade the maximum heat emitted from the sun to the earth surface is $E=0.532 \mathrm{~kW} / \mathrm{m}^{2}$ in winter, and $E=1.096 \mathrm{~kW} / \mathrm{m}^{2}$ in summer. The exposed bodies partially absorb this heat. The body absorptivity constant $\alpha_{s}$ determines the grade of the absorption. An appropriate value for gray coloured cable surface $[1,2]$ is adopted as $\alpha_{\mathrm{s}}=0.4$.

\section{ANALYTICAL METHODS FOR CABLE RATING}

\subsection{Basic ampacity expression}

The permissible current rating of an AC cable laid in free air [1], protected from solar radiation and directly exposed to solar radiation, respectively, is given by:

$$
\begin{aligned}
& I=\left[\frac{\vartheta_{c}-\vartheta_{a}-P_{d}\left[0.5 T_{1}+n\left(T_{2}+T_{3}+T_{4}\right)\right]}{R T_{1}+n R\left(1+\lambda_{1}\right) T_{2}+n R\left(1+\lambda_{1}+\lambda_{2}\right)\left(T_{3}+T_{4}\right)}\right]^{\frac{1}{2}} \\
& I=\left[\frac{\vartheta_{c}-\vartheta_{a}-P_{d}\left[0.5 T_{1}+n\left(T_{2}+T_{3}+T_{4 r}\right)\right]-P_{s} T_{4 r}}{R T_{1}+n R\left(1+\lambda_{1}\right) T_{2}+n R\left(1+\lambda_{1}+\lambda_{2}\right)\left(T_{3}+T_{4 r}\right)}\right]^{\frac{1}{2}}
\end{aligned}
$$

where $\vartheta_{c}$ is the maximum operating temperature of the conductor, $\vartheta_{a}$ is the ambient temperature, $R$ is the alternating current resistance per unit length of the conductor at its maximum operating temperature. Parameter $n$ is the number of conductors in the bunch of cables, $T_{l}$ is the thermal resistance per unit length between one conductor and the sheath, $T_{2}$ is the thermal resistance per unit length of the bedding between the sheath and the armor, and $T_{3}$ is the thermal resistance per unit length of the external insulation of the cable.

Symbol $T_{4}$ designates the thermal resistance per unit length between the cable surface and the surrounding medium for cables protected from solar radiation, $T_{4 r}$ designates the thermal resistance per unit length between the cable surface and the surrounding medium adjusted to take into account solar radiation, $\lambda_{1}$ and $\lambda_{2}$ are ratios of the total losses in metallic sheaths and armour to the total conductor losses, $P_{d}$ are dielectric losses per unit length per phase, and $P_{S}$ is the solar heating per unit length.

The permissible current rating of an AC cable laid in free air [5], in the general form, is given by:

$$
I=\left[\frac{\vartheta_{c}-\vartheta_{a}-P_{d}\left[0.5 T_{1}+n\left(T_{2}+T_{3}+T_{4}\right)\right]-P_{s} T_{4 r}}{R T_{1}+n R\left(1+\lambda_{1}\right) T_{2}+n R\left(1+\lambda_{1}+\lambda_{2}\right)\left(T_{3}+T_{4}\right)}\right]^{\frac{1}{2}}
$$

All methods of analytical calculation for load capacity relate to cables installed in the horizontal plane. Whether the mounting is vertical or horizontal has, in principle, no influence on the heat dissipated by radiation [2].

The heat dissipated by convection from a vertical cylinder of length $l$ and diameter $d_{s}$ with all other condition equal, more favourable than that of the cylinder in horizontal position, provided that [2]

$$
\frac{l}{d_{s}} \geq 2.77
$$

Since this relationship is always satisfied in respect of cables installed in a vertical plane it follows that they can normally withstand heavier loads then when they are installed horizontally. Thus the same load capacity can be applied to both conditions [2]

In this paper, we shall particularly consider the outer thermal resistances $T_{4}, T_{4 r}$ and $P_{s}$ as the available analytical approaches differ in calculation of this parameter.

The expressions for the calculation of other variables are the same for all analytical methods under consideration, and are as given in [1].

\subsection{The IEC Method}

The thermal resistance per unit length between the cable surface and the surrounding medium for cables protected from solar radiation is expressed in the form

$$
T_{4}=\frac{1}{\pi D_{s} h_{1}\left(\Delta \vartheta_{s}\right)^{1 / 4}}
$$

where $D_{s}$ is the overall diameter of the cable bunch, $h_{l}$ is the heat dissipation coefficient and $\Delta \vartheta_{s}$ is excess of cable surface temperature above ambient temperature.

In case under consideration overall diameter of the cable bunch $\mathrm{D}_{\mathrm{s}}=2.312 \cdot \mathrm{d}_{\mathrm{s}}$, where $d_{s}$ is the overall diameter for one cable.

The heat dissipation coefficient is calculated as

$$
h_{1}=\frac{Z}{\left(D_{s}\right)^{b}}+F
$$

In case under consideration $Z=0.96, \mathrm{~F}=1.25$ and $b=0.20$. 
The excess of cable surface temperature above ambient temperature is obtainable by a simple iterative method.

$$
\left(\Delta \vartheta_{s}\right)_{n+1}^{1 / 4}=\left[\frac{\vartheta_{c}-\vartheta_{a}+\Delta \vartheta_{d}}{1+K_{A}\left(\Delta \vartheta_{s}\right)_{n}^{1 / 4}}\right]^{1 / 4}
$$

where

$$
\Delta \vartheta_{d}=P_{d} \cdot\left[\left(\frac{1}{1+\lambda_{1}+\lambda_{2}}-\frac{1}{2}\right) \cdot T_{1}-\frac{n \cdot \lambda_{2} \cdot T_{2}}{1+\lambda_{1}+\lambda_{2}}\right]
$$

where $\Delta \vartheta_{d}$ is temperature rise above ambient temperature due to the dielectric losses and index $n$ designating the number of iterations.

In $(21)$

$$
K_{A}=\frac{\pi D_{s} h_{1}}{\left(1+\lambda_{1}+\lambda_{2}\right)}\left[\frac{T_{1}}{n}+T_{2}\left(1+\lambda_{1}\right)+T_{3}\left(1+\lambda_{1}+\lambda_{2}\right)\right]
$$

The initial value of $\Delta \vartheta_{s}$ is $\left(\Delta \vartheta_{s}\right)_{1}^{1 / 4}=2$. Iterative procedure terminates when

$$
\left(\Delta \vartheta_{s}\right)_{n+1}^{1 / 4}-\left(\Delta \vartheta_{s}\right)_{n}^{1 / 4} \leq 0.001
$$

Where cables are directly exposed to solar radiation, thermal resistance $T_{4 r}$ is calculate from equation

$$
T_{4 r}=\frac{1}{\pi D_{s} h_{1}\left(\Delta \vartheta_{s}\right)^{1 / 4}}
$$

by the previous method except that in the iterative method $\left(\Delta \vartheta_{s}\right)^{1 / 4}$ is calculated using the following formula:

$$
\left(\Delta \vartheta_{s}\right)_{n+1}^{1 / 4}=\left[\frac{\vartheta_{c}-\vartheta_{a}+\Delta \vartheta_{d}+\Delta \vartheta_{d s}}{1+K_{A}\left(\Delta \vartheta_{s}\right)_{n}^{1 / 4}}\right]^{1 / 4}
$$

where

$$
\Delta \vartheta_{d s}=\frac{P_{s}}{\left(1+\lambda_{1}+\lambda_{2}\right)}\left[\frac{T_{1}}{n}+T_{2}\left(1+\lambda_{1}\right)+T_{3}\left(1+\lambda_{1}+\lambda_{2}\right)\right]
$$

and

$$
P_{s}=\alpha_{s} D_{s} E
$$

where $P_{s}$ is the solar heating per unit length, $\alpha_{s}$ is the absorption coefficient of solar radiation for the cable surface and $E$ is maximum heat emitted from the sun to the earth surface.

\subsection{Calculation of resistances $T_{4}, T_{4 r}$ and solar heating $P_{s}$ based on non-dimensional numbers}

The thermal resistance per unit length between the surface of one circular cylinder protected from solar radiation and the surrounding medium $T_{4}$ is expressed in the form [5]

$$
T_{4}=\frac{1}{\pi d_{s}\left(k_{t r}+k_{t c}\right)}
$$

where $d_{s}$ is the overall diameter for one circular cylinder, and $k_{t r}$, and $k_{t c}$ are the coefficients for heat transfers by radiation and convection, respectively.

According to the Stefan-Boltzmann law, the heat transfer coefficient for radiation is:

$$
k_{t r}=\sigma \varepsilon_{0} \frac{\left(273+\vartheta_{s}\right)^{4}-\left(273+\vartheta_{a}\right)^{4}}{\vartheta_{s}-\vartheta_{a}}
$$

where $\vartheta_{s}$ and $\vartheta_{a}$, in ${ }^{0} C$ are cable surface and ambient temperatures, respectively.

The heat transfer coefficient for convection for one circular cylinder is calculated as

$$
k_{t c}=N_{u} \frac{\lambda}{d_{s}}
$$

where $N_{u}$ is the Nusselt number, and $\lambda$ is the thermal conductivity of the fluid at the surface of the cable.

The thermal conductivity for moderate temperatures can be approximated by

$$
\lambda=2.42 \cdot 10^{-2}+3.6 \cdot 10^{-5}\left(\vartheta_{s}+\vartheta_{a}\right)
$$

The Nusselt number for natural convection for one circular cylinder in horizontal position can be expressed as

$$
N_{u}=0.48 \cdot\left(G_{r} P_{r}\right)^{0.25}
$$

where $G_{r}$ is the Grashof number for one circular cylinder and $P_{r}$ is the Prandtl number.

The Grashof number for one circular cylinder is

$$
G_{r}=\frac{d_{s}^{3} \cdot g \cdot\left(\vartheta_{s}-\vartheta_{a}\right)}{\left[0.5 \cdot\left(\vartheta_{s}+\vartheta_{a}\right)+273\right] \cdot v\left(H_{a}\right)^{2}}
$$

where $g$ is the acceleration due to gravity, and $v\left(H_{a}\right)$ is the kinematics' viscosity of the fluid at the surface of the cable at height $H_{a}$ above sea level.

Kinematics' viscosity of the fluid at sea level for moderate temperatures can be determined as

$$
\begin{aligned}
& v(0)=1.32 \cdot 10^{-5}+ \\
& +4.75 \cdot 10^{-8}\left(\vartheta_{s}+\vartheta_{a}\right)
\end{aligned}
$$

at height $H_{a}$ above sea level this viscosity is

$$
v\left(H_{a}\right)=v(0) \cdot\left(1-\frac{6.5 \cdot 10^{-3} \cdot H_{a}}{288.16}\right)^{-5.2561}
$$


The Prandtl number for moderate temperatures can be determined as

$$
P_{r}=0.715-1.25 \cdot 10^{-4}\left(\vartheta_{s}+\vartheta_{a}\right)
$$

The Nusselt number for natural convection for three cables in trefoil formation in horizontal position is also calculated by equation (33) where the Grashof number for one circular cylinder is substituted by Grashof number for three cables in trefoil formation.

The Grashof number for three cables in the trefoil formation is calculated by equation (34) where $d_{s}$ are substituted by $d_{e k}$. In the case of three cables in trefoil formation $d_{e k}$ is equal to $2.155 d_{s}$ [5].According to the previous Nusselt number for natural convection for three cables in trefoil formation is calculated by equation (33) where $d_{s}$ is substituted by $d_{e k}$.

Finally, the thermal resistance per unit length between the cable surface and the surrounding medium for cables protected from solar radiation $T_{4}$ is expressed in the form [5]

$$
T_{4}=\frac{1}{\pi d_{e k}\left(f_{r} k_{t r}+k_{t c}\right)}
$$

where $f_{r}$ is the factor for the interchange of radiation energy between the surfaces of the conductors of the cable bunch.

The factor $f_{r}$ for two long parallel circular cylinders is, according to [5],

$$
f_{r}=\frac{1}{\pi}\left\{\frac{\pi}{2}+\left[\frac{s^{2}}{d_{s}^{2}}+\frac{2 s}{d_{s}}\right]^{\frac{1}{2}}-\left(1+\frac{s}{d_{s}}\right)-\cos ^{-1}\left[\frac{1}{1+\frac{s}{d_{s}}}\right]\right\}
$$

where $s$ is the spacing between surface of cylinders. In the case of three cables in trefoil formation, this factor is equal to 0.636 .

The thermal resistance between the cable surface and the surrounding medium adjusted to take into account solar radiation is expressed in the form

$$
T_{4 r}=\frac{1}{\pi d_{e k} k_{t r}}
$$

The factors that define the incident surface of radiation are specifically determined for each type of incident solar radiation.

The total solar heat input per unit length may be expressed as the sum from beam radiation, diffuse radiation, long-wave radiation and reflected radiation. In case of consideration we assumed that diffuse radiation, long-wave radiation and reflected radiation are neglected.
The heat input from the beam radiation for one circular cylinder is defined by

$$
P_{S B}=\alpha_{S} \cdot d_{S} \cdot I_{B}\left(H_{a}\right) \cdot f_{S B} \cdot \sin \eta
$$

where $\alpha_{s}$ is the absorptive surface to short-wave radiation, $I_{B}$ is the direct-beam short-wave radiation flux at high $H_{a}$ above sea level, $f_{S B}$ is the coefficient of exposed projected area normal to the direct beam defined for each conductor, and $\eta$ is the angle between the solar beam and the axis of the three cables in the trefoil formation. Average high above sea level in Belgrade is $150 \mathrm{~m}$.

The heat input from the beam radiation for three cables in the trefoil formation is calculated by equation (41) where $d_{s}$ are substituted by $d_{e k}$.

The direct-beam short-wave radiation flux at high $H_{a}$ above sea level is calculate from equation

$$
I_{B}\left(H_{a}\right)=N_{s} \cdot I_{B}(0) \cdot\left[1+1.4 \cdot 10^{-4} \cdot H_{a} \cdot\left(\frac{I_{0}}{I_{B}(0)}-1\right)\right]
$$

where $N_{s}$ is clarity of the sky (for clear sky $N_{s}=$ $0.7), I_{B}(0)$ is the direct-beam short-wave radiation flux at sea level and $I_{0}$ is daily heat emitted from the sun to the earth surface.

The direct-beam short-wave radiation flux at sea level is calculate from equation

$$
I_{B}(0)=\frac{1280 \cdot \sin \psi_{s}}{\sin \psi_{s}+0.314}
$$

where $\psi_{s}$ is angle of sunset from the ground.

Daily heat emitted from the sun to the earth surface is given by

$$
I_{0}=E \cdot\left[1+0.033 \cdot \cos \left(\frac{2 \pi \cdot N}{365}\right)\right]
$$

where $E$ is maximum heat emitted from the sun to the earth surface, and $N$ is day in year $(\mathrm{N}=1$ is first January).

The angle of sunset from the ground is calculate from equation

$$
\begin{aligned}
& \sin \psi_{s}=\sin \delta_{s} \cdot \sin \varphi+ \\
& +\cos \delta_{s} \cdot \cos \varphi \cdot \cos \omega_{s}
\end{aligned}
$$

where $\delta_{s}$ is declination of the sun, $\varphi$ is latitude, and $\omega_{s}$ is time angle. Latitude for Belgrade is $44^{\circ} 48^{\prime}$ north.

The declination of the sun is given by

$$
\delta_{s}=23.45 \cdot \sin \left[\frac{360 \cdot(284+N)}{365.24}\right]
$$



from

Time angle at any time after sunrise is calculate

$$
\omega_{s}=15 \cdot\left(t_{s}-12\right)
$$

where $t_{s}$ is local apparent time.

The local apparent time is given by

$$
t_{s}=t+t_{\varphi}+t_{e t}
$$

where $t$ is official time for the first standard meridian, $t_{\varphi}$ is time correction due to geographical length, and $t_{e t}$ is uniformity of time.

The correction of time due to the geographical length is four minutes per degree and is positive for the local meridian east of the standard meridian. The geographical length for Belgrade is $20^{\circ} 28^{\prime}$ east.

The uniformity of time is given by

$$
\begin{aligned}
& t_{e t}=2.8648 \cdot 10^{-4}+7.1352 \cdot 10^{-3} \cdot \cos \theta_{N}- \\
& -0.12253 \cdot \sin \theta_{N}- \\
& -5.5825 \cdot 10^{-2} \cdot \cos 2 \theta_{N}-0.15603 \cdot \sin 2 \theta_{N}
\end{aligned}
$$

where

$$
\theta_{N}=\frac{2 \pi \cdot(N-1)}{365}
$$

The angle between the solar beam and the axis of the three cables in the trefoil formation is calculate from equation

$$
\begin{aligned}
& \cos \eta=\cos \xi \cdot \cos \psi_{s} \cdot \cos \left(\gamma_{s}-\gamma_{L}\right)+ \\
& +\sin \xi \cdot \sin \psi_{s}
\end{aligned}
$$

where $\xi$ is inclination of cable bunch to horizontal, $\gamma_{s}$ is azimuth of the sun, and $\gamma_{L}$ is azimuth of the cable bunch. The azimuth of the cable bunch is measured in the direction of the cursor on the clock from the south.

Azimuth of the sun is given by

$$
\cos \gamma_{s}=\frac{\sin \varphi \cdot \sin \psi_{s}-\sin \delta_{s}}{\cos \varphi \cdot \cos \psi_{s}}
$$

The coefficient of the exposed projected area normal to the direct beam defined for cable bunch is given by

$$
\begin{aligned}
& f_{S B}=\frac{1+\sin \eta+\sin \left(60^{\circ}-\eta\right)}{3} ; 0^{\circ}<\eta<60^{\circ} \\
& f_{S B}=\frac{1+\sin \eta}{3} ; 60^{\circ} \leq \eta \leq 120^{\circ} \\
& f_{S B}=\frac{1+\sin \eta+\sin \left(\eta-120^{\circ}\right)}{3} ; \\
& 120<\eta<180^{\circ}
\end{aligned}
$$

\section{APPLICATION}

\subsection{Cable data}

The approaches presented in the preceding sections have been applied to determine the maximum allowable continuous current of the three phases 110 $\mathrm{kV}$ XHE 49 - A $3 \times 1000 \mathrm{~mm}^{2}$ cable bunch in trefoil formation, presented in Figure 1. Table 1 gives the main data on relevant materials of the cable under consideration.

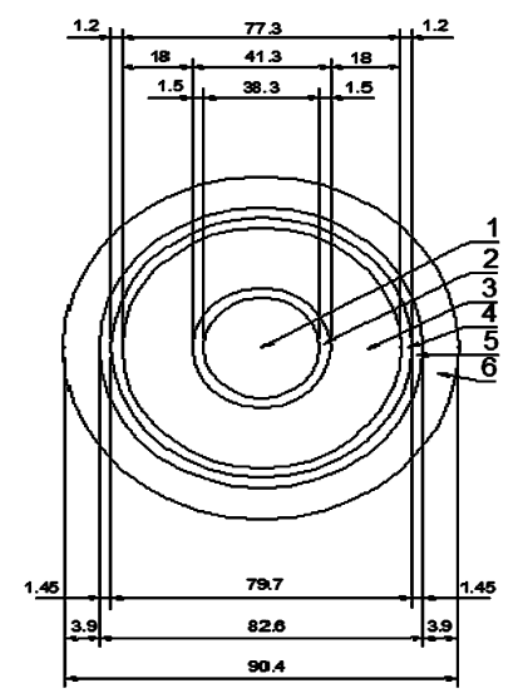

Figure 1 - Cross section of the $110 \mathrm{kV}$ XHE-A cable

1- Aluminium conductor; 2- conductor screen; 3cross-linked PE insulation; 4- cross-linked PE insulation screen; 5- copper wires and counter helix copper tape metallic screen; 6- high density polyethylene outer sheath. All measures are in (mm).

Table 1.Data for relevant materials

\begin{tabular}{|l|l|l|l|}
\hline \hline Material & $\begin{array}{l}\text { Conduction } \\
\text { coefficient } \\
\mathrm{k} \\
(\mathrm{W} / \mathrm{Km})\end{array}$ & $\begin{array}{l}\rho \\
\left(\mathrm{kg} / \mathrm{dm}^{3}\right)\end{array}$ & $\begin{array}{l}\text { Specific heat } \\
(\mathrm{J} /(\mathrm{Kkg})) \times 10^{3}\end{array}$ \\
\hline $\begin{array}{l}\text { Aluminium } \\
\text { conductor }\end{array}$ & 220 & 2.70 & 0.919 \\
\hline Insulation & 0.286 & 0.93 & 3.978 \\
\hline $\begin{array}{l}\text { Cooper } \\
\text { screen }\end{array}$ & 385 & 8.92 & 0.393 \\
\hline Outersheath & 0.286 & 0.92 & 2.610 \\
\hline \hline
\end{tabular}

Maximum permissible conductor temperature for normal conditions is $\vartheta_{m}=90{ }^{\circ} \mathrm{C}$. Aluminium conductor and copper screen Joule losses at $\vartheta_{m}$ are $0.0408 \times I^{2} \mathrm{x}$ $10^{-2}$ and $0.0271 \times I^{2} \times 10^{-2}$, while dielectric losses at rated voltage are 1.193, respectively, with all losses expressed in $W / m$. $I$ is the rms of the continuous load current at which the conductors have reached the maximum allowable temperature. 


\subsection{The finite element mesh}

Figure 2 displays the finite element mesh for three cables in trefoil formation constructed for the analysis of temperature distribution.
Total number of nodes for the network of finiteelements mesh is 98 . The number of triangular finiteelement of: aluminium conductor is 24 , insulation is 48 , cooper screen is 48 , and outer sheath is 52 .

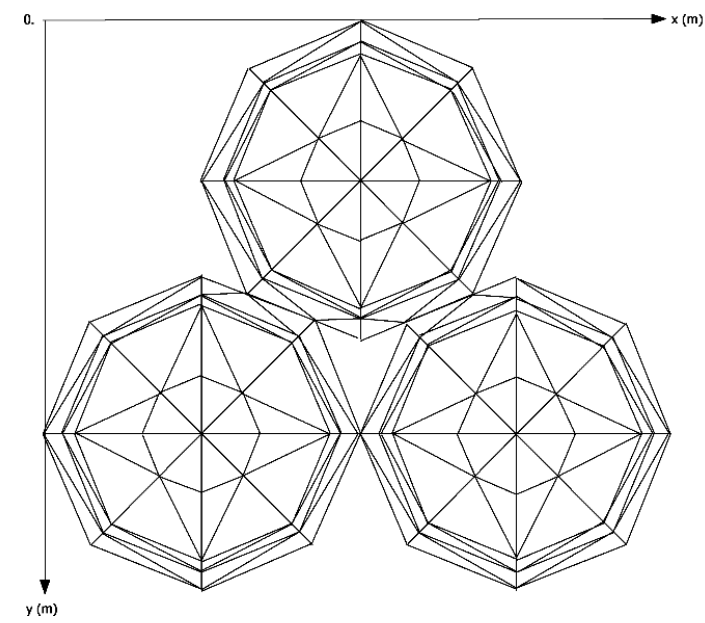

Figure 2 - Finite element mesh of three cables in trefoil formation. All measures are in (m).

\subsection{Results of calculations for various approaches}

The maximum allowable continues current for the three cables in trefoil formation has been calculated by applying the finite element method and the numerical approaches presented before. Table 2 gives the maximum allowable load currents for the cable bunch determined by applying different calculation approaches discussed in this paper. The methods under consideration have been applied to determine the ampacity of the bunch of cables in the cases that the ambient temperatures are $25{ }^{\circ} \mathrm{C}$ and $40^{\circ} \mathrm{C}$ for cables protected from solar radiation and directly exposed to solar radiation and compare with catalogue data [15].

Table 2. Ampacity of the bunch of cables

\begin{tabular}{|c|c|c|c|c|c|c|c|}
\hline \multirow{2}{*}{$\begin{array}{c}\vartheta_{a} \\
{ }^{\circ} \mathrm{C}\end{array}$} & \multicolumn{3}{|c|}{ Cables protected from } & solar radiation & \multicolumn{3}{|c|}{$\begin{array}{l}\text { Cables directly exposed to solar } \\
\text { radiation }\end{array}$} \\
\hline & $\begin{array}{l}\text { Catalogue } \\
\text { data } \\
\text { A }\end{array}$ & $\begin{array}{l}\text { FEM } \\
\text { A }\end{array}$ & $\begin{array}{l}I_{3.2} \\
\mathrm{~A}\end{array}$ & $\begin{array}{l}I_{3.3} \\
\mathrm{~A}\end{array}$ & $\begin{array}{l}\text { FEM } \\
\text { A }\end{array}$ & $\begin{array}{l}I_{3.2} \\
\mathrm{~A}\end{array}$ & $\begin{array}{l}I_{3.3} \\
\mathrm{~A}\end{array}$ \\
\hline 25 & 1145.0 & 1146.0 & 1069.0 & 1133.5 & 1002.0 & 893.5 & 1041.3 \\
\hline 40 & - & 1038.0 & 919.1 & 985.8 & 878.0 & 700.5 & 887.8 \\
\hline
\end{tabular}

The finite element method and analytical approach based on non-dimensional numbers [5] respect heat exchange between the cable surface and the surrounding medium by convection and radiation as opposed to the IEC method that only regards radiation.

Therefore, in both cases for cables protected from solar radiation and cables directly exposed to solar radiation, the IEC method gives lower values of permitted current loads from the finite element method and analytical approach based on non-dimensional numbers.

As can be seen, ampacity calculated by finite element method and analytical approach based on nondimensional numbers for cables protected from solar radiation, gives value $1 \mathrm{~A}$ higher and $11.5 \mathrm{~A}$ lower to the given catalog value for ambient temperature $\vartheta_{a}=25^{\circ} \mathrm{C}$, respectively. The comparative calculations have been also performed for the ambient temperature $\vartheta_{a}=40{ }^{\circ} \mathrm{C}$, and finite element method has again gives the results higher than the analytical approaches.

Higher values for ampacity calculated by finite element method for cables protected from solar radiation is due to the fact that the actual temperature is taken into account for each point on the outer surface of the cable bunch, while the analytical approach based on non-dimensional numbers for all points on the outer surface of the cable bunch takes into account only one temperature (in our case $\vartheta_{s}=65^{\circ} \mathrm{C}$ ).

The influence of solar radiation in summer on the reduction of the maximum allowable continues current for the three cables in trefoil formation is in the finite element method about $145 A$, in the IEC method about $190 \mathrm{~A}$, and in the case of analytical approach based on non-dimensional numbers about $95 \mathrm{~A}$. The effect of the 
incident angle between the solar beam and the axis of the three cables in the trefoil formation to reduce the maximum allowable continues current is not respected in the IEC method, and therefore the reduction of the allowable continues current due to solar radiation is the greatest in this method. The incident angle of the solar beam is calculated in the case of the analytical approach based on non-dimensional numbers in relation to the three cables in the trefoil formation, while in the FEM, the incident angle of the solar beam is calculated for each individual triangular finite element.

\section{TIME CHANGES OF CONDUCTOR TEMPERATURE DURING HEATING- COOLING CYCLE}

It is of particular importance to determine the time constants for heating and cooling cycles for the three $\mathrm{HV}$ cables in trefoil formation laid in free air. Specifically, if the time constants of heating and cooling cycles are greater than 1 hour, then the thermal capacity of the cable bunch can be used in the control of the load flow in real-time.

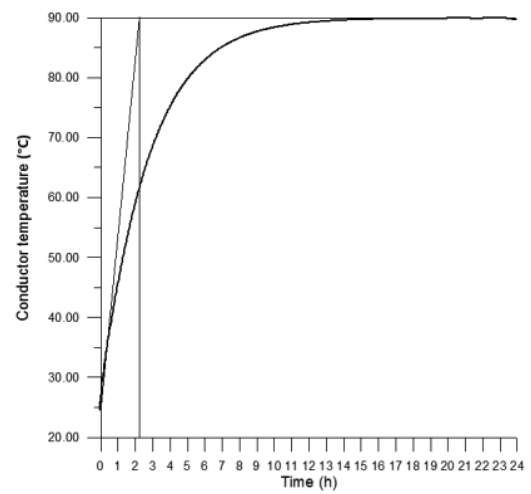

Figure 3 - Variations of conductor temperature during a heating cycle

Figure 3 and Figure 4 presents the calculations variations of conductor temperatures during a heating and cooling cycle, respectively.

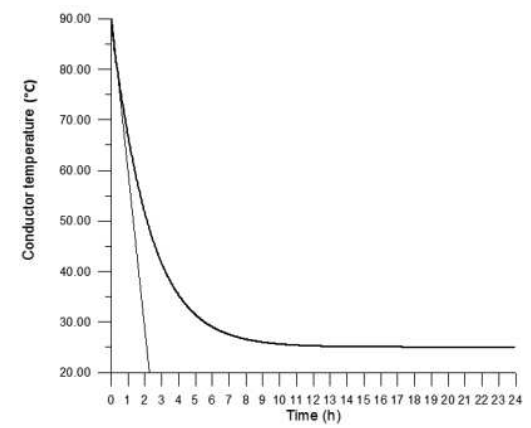

Figure 4 - Variations of conductor temperature during a cooling cycle

The time constants for heating and cooling cycles are 2 hours and 15 minutes and are determined by the graphic procedure of Figure 3 and Figure 4.

\section{CONCLUSION}

The paper presents various methods for the calculation of the continuous current rating of a three $\mathrm{AC}$ cables in trefoil formation laid in free air. A finite element model conceived for this analysis has been presented as well as two different analytical approaches used in practice. The results obtained by all considered methods have been compared to the catalogue data. It has been shown that MKE and analytical approach based on non-dimensional numbers give ratings that very slightly differ from catalogue data. The best agreement to the catalogue data has been achieved by the finite element method. Particular consideration is given to the influence of solar radiation on the permissible current rating for all shown methods. The developed FE model has been also used for the calculation of the time constants for heating-cooling cycle for the considered bunch of cables.

\section{APPENDIX A. PARAMETERS OF TRIANGULAR FINITE ELEMENTS}

Triangular finite-elements that are adopted for modelling the interaction of cables and pipelines are shown in Fig.5.

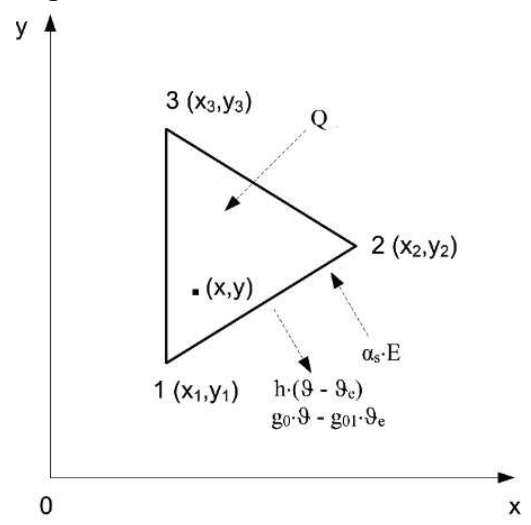

Figure 5 - Triangular finite-element

The parameters figuring in the heat transfer equations (1) - (3) for a triangular finite-element are [11 13]

$$
\begin{aligned}
& {[C]=\frac{1}{12} \rho c d S\left[\begin{array}{lll}
2 & 1 & 1 \\
1 & 2 & 1 \\
1 & 1 & 2
\end{array}\right]} \\
& {\left[K_{c}\right]=k d S[B]^{T}[B]} \\
& {[B]=\frac{1}{2 S}\left[\begin{array}{lll}
b_{1} & b_{2} & b_{3} \\
c_{1} & c_{2} & c_{3}
\end{array}\right]}
\end{aligned}
$$

$b_{1}=y_{2}-y_{3}, \quad b_{2}=y_{3}-y_{1}, \quad b_{3}=y_{1}-y_{2}$ $c_{1}=x_{2}-x_{3}, \quad c_{2}=x_{3}-x_{1}, \quad c_{3}=x_{1}-x_{2}$ 


$$
\begin{aligned}
& {\left[K_{h}\right]=\frac{1}{6} h d l_{12}\left[\begin{array}{lll}
2 & 1 & 0 \\
1 & 2 & 0 \\
0 & 0 & 0
\end{array}\right]} \\
& {\left[K_{r}\right]=\frac{1}{6} g_{0} d l_{12}\left[\begin{array}{lll}
2 & 1 & 0 \\
1 & 2 & 0 \\
0 & 0 & 0
\end{array}\right]} \\
& {\left[R_{Q}\right]=\frac{1}{3} Q(t) d S\left[\begin{array}{l}
1 \\
1 \\
1
\end{array}\right]} \\
& {\left[R_{h}(t)\right]=\frac{1}{2} \vartheta_{e}(t) h d l_{12}\left[\begin{array}{l}
1 \\
1 \\
0
\end{array}\right]} \\
& {\left[R_{r}(t)\right]=\frac{1}{2} \vartheta_{e}(t) g_{01} d l_{12}\left[\begin{array}{l}
1 \\
1 \\
0
\end{array}\right]} \\
& {\left[R_{s}\right]=\frac{1}{2} \alpha_{s} E d l_{12}\left[\begin{array}{l}
1 \\
1 \\
0
\end{array}\right]}
\end{aligned}
$$

In above given expressions $\rho$ and $c$ are material density and specific heat capacity, $S$ and $d$ are triangle area and axial length of cable section, $k$ and $h$ are conduction and convection factors, $x_{k}$ and $y_{k}$ connecting nodes 1 and $2, Q(t)$ is the heat generated inside the element, $\vartheta_{e}(t)$ is the air temperature, $E$ is emitted heat from the sun to the earth surface during an average winter or summer day, and $\alpha_{s}$ is the absorption coefficient of the gray coloured cable surface.

As can be seen from the expressions above, all ter$\mathrm{ms}$ in (A.1), (A.2) and (A.5) to (A.10) are proportional to $d$ and these relationships hold for all values of this parameter. The adopted value in this analysis was $\mathrm{d}=1$ $m$. $\mathrm{x}_{\mathrm{k}}$ and $\mathrm{y}_{\mathrm{k}}, k=1,2,3$, are plane rectangular coordinates of triangular element nodes. $l_{12}$ is the length of triangle edge connecting points 1 and 2 . In deriving the expressions listed above, it is assumed that the triangular element exchanges the heat by convection through its edge connecting nodes 1 and 2 .

\section{REFERENCES}

[1] IEC Publication 287, "Calculation of the continuous current rating of cables ( $100 \%$ load factor)", Geneva, Suisse, 1982.

[2] Heinhold, Power Cables and Their Applications, Third Edition, Siemens Aktiengeselschaft, Erlangen, 1990.
[3] S. Liu, and H. Han, "Analytical method of calculating the transient and steady-state temperature rises for cable-bundle in tray and ladder", IEEE Trans. on Power Delivery, vol.13 No 3, pp .691-98, July 1998.

[4] P. Pollak, "Neher-McGrath Calculations for Insulated Power cables", IEEE Trans. on Industry Applications, vol.IA-21 No.5, September/October 1985.

[5] V.T. Morgan, "Thermal Behaviours of Electrical Conductors", Research Studies Press Ltd., Tounton, Somerset, England, 1991.

[6] D.A. Douglass, "Radial and axial temperature gradients in hare stranded conductor", IEEE Trans. on Power Delivery, vol.PWRD-1 No 2, April 1986.

[7] N. Flatabo, "Transient heat conduction problems in power cables solved by the finite element method", IEEE PES Summer Meeting, No T 72 508-0, San Francisco, July 9-14, 1972.

[8] D. Mushamalirwa, N. Germay, and J. C. Streffens, "A 2-D finite element mesh generator for thermal analysis of underground power cables", IEEE Trans. on Power Delivery, vol.3 No.1, pp. 62-68, January 1988.

[9] G. J. Anders, N. Chaaban, N. Bedart, and R. W. D. Ganton, "New approach to ampacity evaluation of cables in ducts using finite element technique", IEEE Trans. Power Delivery, vol.2 No.4, pp.969-975, October 1987.

[10] J. Nahman, and M. Tanaskovic, "Determination of the current carrying capacity of cables using the finite element method", Electric Power Systems Research vol. 61, pp.109-117, 2002.

[11] J. Nahman, M. Tanaskovic, "Calculation of the ampacity of high voltage cables by accounting for radiation and solar heating effects using FEM". Article first published online: 14 DEC 2011. DOI: 10.1002/etep.660. Copyright (C) 2011 John Wiley \& Sons.

[12] J. Nahman, M. Tanaskovic,Calculation of the ampacity of medium voltage self-supporting cable bunch, Electris Power Systems Research vol.93, pp.106$112,2012$.

[13] K. Huebner, and E. Thornton, "The Finite Element Method for Engineers", J. Wiley \& Sons, New York, 1982.

[14] A. Chapman, "Heat Transfer" (Third Ed.), Macmillan Publ. Comp., New York 1974.

[15] FKS, Yugoslavia: High Voltage Cables Insulation of Cross-Linked Polyethylene. 


\section{REZIME}

\section{PRORAČUN STRUJNOG OPTEREĆENJA VISOKONAPONSKIH KABLOVA SLOBODNO POSTAVLJENIH U VAZDUHU}

Članak prikazuje različite pristupe za određivanje strujnog opterećenja tri $110 \mathrm{kV}$ kabla slobodno postavljena u vazduhu u trougaonom rasporedu uključujući razvijeni metod konačnim elementima. Svi modeli mogu da uvaže sve okolnosti koje utiču na strujno opterećenje kablova uključujući prenos toplote u okolni ambijent zračenjem i strujanjem, kao i efekat zagrevanja od Sunca. Pokazano je da su svi dostupni pristupi dali rezultate koji se podudaraju sa zadovoljavajućom tačnošću. Dozvoljeno strujno opterećenje za tri kabla naizmeničnog napona u trougaonom rasporedu slobodno postavljena u vazduhu je izračunato za letnji period za kablove zaštićene od sunčevog zračenja i kablove direktno izložene sunčevom zračenju. Takođe, izračunate su vremenske konstante za razmatrani kablovski snop za ciklus grejanje-hlađenje. Važno je napomenuti, da je strujno opterećenje tri kabla u trougaonom rasporedu, svim primenjenim metodama, određeno izostavljanjem hlađenja od vetra kako bi se dobili rezultati za najgore uslove.

Ključne reči: strujno opterećenje visokonaponskih kablova slobodno postavljenih u vazduhu, Metod konačnih elemenata i analitički metodi, tri kabla u trougaonom rasporedu 